\title{
Congenital cystic adenomatoid malformation case diagnosed in the first six months of life and application of HFOV in respiratory failure due to pneumothorax
}

\author{
Yaşamın altıncı ayında tanımlanmış kistik adenomatoid malformasyon \\ olgusu ve pnömotoraksa bağlı solunum yetmezliğinde HFOV uygulaması
}

\author{
Seher ERDOĞAN, Arzu OTO, Mehmet BOŞNAK
}

\section{SUMMARY}

Patient who had pneumothorax and suffered convulsion during chest tube revision was intubated due to respiratory failure and transferred from the service of the department of Children's Health, and Diseases to its intensive care unit. The patient was ventilated in SIMV-PS (synchronized intermittent mandatory ventilation-pressure support) mode by mechanical ventilator. Control blood gas $\mathrm{pH}$ and $\mathrm{pCO}_{2}$ values were 7.01 and $115 \mathrm{mmHg}$, respectively. Then, the patient was weaned from mechanical ventilation and high-frequency oscilatory ventilation application was started. Respiratory acidosis improved and the oxygenation index decreased during blood gas monitoring. On the $7^{\text {th }}$ day, patient was connected to conventional mechanical ventilation. Pulmonary wedge resection was performed for diagnostic purposes. Cystic adenomatoid malformation was diagnosed histopatologically. Patient was gradually separated from the ventilator on the $26^{\text {th }}$ day of hospitalization. Chest tube was withdrawn and the patient was transferred to the ward of the department of pediatrics.

Key words: Congenital cystic adenomatoid malformation, highfrequency oscillatory ventilation, pneumothorax, respiratory failure
ÖZET

Hastanemiz Pediatri Servisinde pnömotoraks nedeniyle izlenen ve göğüs tüpü revizyonu sırasında konvülziyon geçiren hasta, solunum yetmezliği nedeniyle entübe edilerek Çocuk Yoğun Bakım Ünitesine transfer edildi. Hasta mekanik ventilatörde SIMV-PS (basınç destekli senkronize aralıklı zorunlu ventilasyon) modunda solutuldu. Bakılan kontrol kan gazında $\mathrm{pH}: 7,01$ ve $\mathrm{pCO}_{2}: 115$ $\mathrm{mmHg}$ olması nedeniyle hasta mekanik ventilatörden ayrıldı ve yüksek frekans ossilasyon ventilasyon uygulaması başlatıldı. Kan gazı takiplerinde respiratuvar asidozun düzeldiği ve oksijenasyon indeksinin azaldığı görüldü. Yedinci günde konvansiyonel mekanik ventilasyona geçildi. Tanısal amaçlı akciğer wedge rezeksiyon yapıldı, patolojik incelemede kistik adenomatoid malformasyon tanısı kondu. Yatışının 26. gününde kademeli olarak ventilatörden ayrıldı, ekstübe edildi. Gögüs tüpü çekilen ve vital bulguları stabil seyreden hasta pediatri servisine devredildi.

Anahtar kelimeler: Konjenital kistik adenomatoid malformasyon, yüksek frekanslı osilatör ventilasyonu, pnömotoraks, solunum yetmezliği
GiRiş

Konjenital kistik adenomatoid malformasyon (KKAM) nadir, ancak yaşamı tehdit edebilen bir akciğer anomalisidir. Gestasyonun 6.-8. haftasında ortaya çıkan, proksimal hava yollarında matürasyon eksikliğine, alveollerde genişlemenin eşlik ettiği bir embriyolojik gelişim eksikliğidir. Değişen hacimlerde ve birbirleri ile anastomozlar gösteren prolifere terminal bronşioller ve kistler ile karakterizedir ${ }^{1}$. Insidansı 1/8300-
1/35000 olarak belirtilmektedir. Sporadik olarak görülür, oluşumunda annenin yaşı, ırkı, ilaç ya da toksik madde maruziyetinin etkisi yoktur ${ }^{2}$. Yenidoğan döneminde ciddi ve ilerleyici solunum sıkıntısına, çocuk ya da yetişkinlerde ise yineleyen akciğer infeksiyonlarına neden olur. Öksürük, dispne ve siyanoz yakınmaları bulunabilir. Spontan pnömotoraks olabilir. Prenatal KKAM tanısı alan hastaların yaklaşık yarısı doğum sırasında asemptomatiktir. KKAM olgularının $1 / 3^{\prime} i$ yenidoğan döneminden sonra tanı alırlar ${ }^{3,4}$. 
Yineleyen pnömotoraks nedeniyle yatırılan, konjenital kistik malformasyon tanısı alan ve solunum destek tedavisi yüksek frekans ossilasyon ventilasyonu ile yürütülen 6 aylık kız hasta sunulmuştur.

\section{OLGU SUNUMU}

Hastanemiz Pediatri Servisinde pnömotoraks nedeniyle izlenen ve göğüs tüpü revizyonu sırasında konvülziyon geçiren hasta, solunum yetmezliği nedeniyle entübe edilerek Çocuk Yoğun Bakım Ünitesine transfer edildi. Altı aylık kız hastanın, 26 yaşındaki annenin 2. gebeliğinden 2. canlı doğum olarak miadında 3300 g olarak normal spontan vajinal yolla doğduğu öğrenildi. Anne baba arasında akrabalık yoktu, diğer kardeşi sağlıklı idi. Hastanın 3 aylıkken ateş ve solunum sıkıntısı nedeniyle başvurduğu hastanede akciğer enfeksiyonu tanısı ile 20 gün yatırılarak tedavi edildiği öğrenildi. Beş aylıkken benzer yakınmalarla aynı hastaneye başvurduğu, ateş etiyolojisi araştırılmak üzere servise yatırıldığı, ancak yatışının 2. gününde solunum sıkıntısının artması üzerine yinelenen akciğer grafisinde pnömotoraks saptandığı ve göğüs tüpü yerleştirildiği belirtildi. Yoğun bakım takibi sırasında klinik ve radyolojik bulgularda düzelme olması nedeniyle 3 kez göğüs tüpünün çekildiği, yeniden pnömotoraks oluşması nedeniyle hastanemiz pediatri servisine sevk edildiği öğrenildi.

Çocuk Yoğun Bakım Ünitesine kabulünde bilinci kapalı ve entübe idi. Ateş $36,7^{\circ} \mathrm{C}$, solunum sayısı: $47 /$ dk., nabız 130/dk., kan basıncı 101/40 mmHg idi. Gögüs çapı artmıştı ve sol hemitoraks daha belirgindi, solda solunum sesleri azalmıştı ve solda göğüs tüpü mevcuttu. Diğer fizik muayene bulguları doğaldı. Hasta mekanik ventilatörde SIMV-PS modunda solutuldu. Mekanik ventilatör parametreleri; PIP:25 cm $\mathrm{H}_{2} \mathrm{O}$, PEEP:5 $\mathrm{H}_{2} \mathrm{O}, \mathrm{F}: 30 / d k$., $\mathrm{FiO}_{2}: 0,6$ olarak belirlendi. Midazolam ve morfin sülfat infüzyonu ile sedasyon analjezi, rokuronyum ile nöromuskuler blokaj sağlandı. Laboratuvar değerlendirmesinde beyaz küre $5600 / \mathrm{mm}^{3}$, hemoglobin $9.7 \mathrm{~g} / \mathrm{dL}$, trombosit sayısı $277.000 / \mathrm{mm}^{3}$ idi. Biyokimyasal parametrelerde serum Albümin:2.3 g/dL, K:3.41 mmol/L, P:2.7 mg/dL, $\mathrm{Mg}: 1.28 \mathrm{mg} / \mathrm{dL}$ dışında diğerleri normaldi. Hipoal- büminemi nedeniyle hastaya $1 \mathrm{~g} / \mathrm{kg}$ albümin IV uygulandı, MgSO4 ve KPO4 IV başlandı. Prokalsitonin $51.2 \mathrm{ng} / \mathrm{mL}$ olması nedeniyle antibiyoterapisi Meropenem + Vankomisin ile değiştirildi. Kan kültüründe üreme olmadı, bakılan Parainfluenza virus IgG, RSV IgG, Legionella pneumophila IgM, Chlamydia pneumonia IgM, Mycoplasma pneumonia IgM, Coxiella burnetti IgM negatif bulundu. PA Akciğer grafisinde sol akciğerde pnömotoraks oluştuğu, solda akciğer dokusunun kollabe olduğu görüldü. Göğüs tüpüne ait görüntü mevcuttu (Resim 1). Toraks Bilgisayarlı Tomografi (BT) incelemesinde solda geniş pnömotoraks alanı izlendi, sol akciğer kısmen kollabe görünümde idi, bilateral akciğer parankiminde yaygın amfizematöz alanlar, konsolidasyon ve infiltrasyon alanları saptandı (Resim 2). Ekokardiyogafi bulguları normaldi, abdominal ultrasonografi incelemesinde

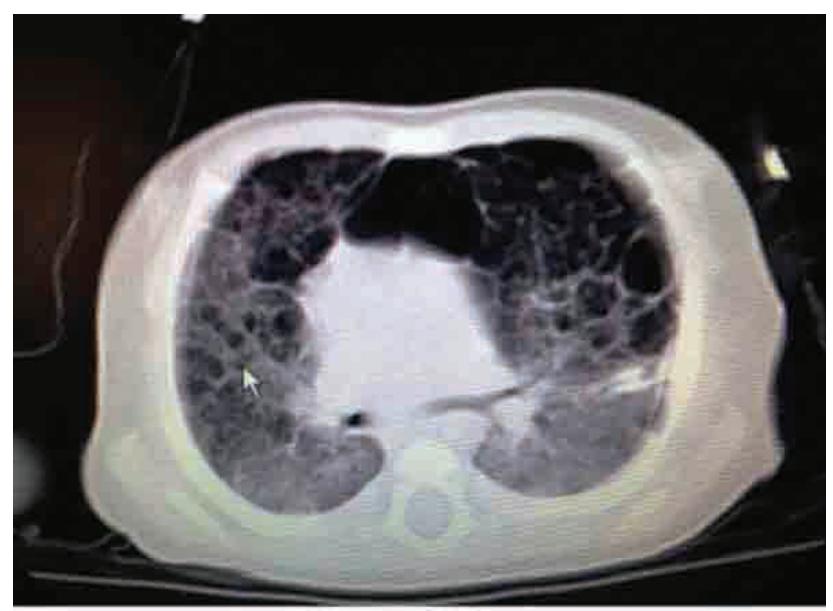

Figür 1. Bilateral akciğer alanlarında yaygın multikistik lezyonlar saptandı.

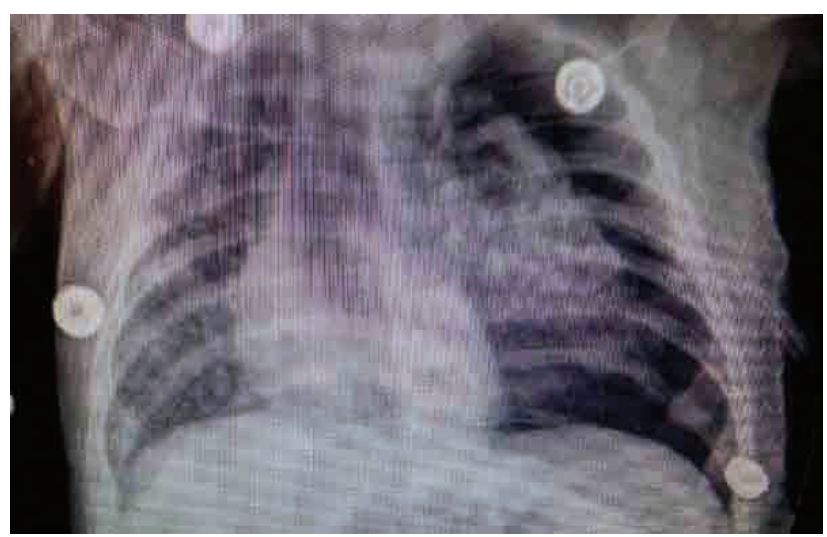

Figür 2. Sol akciğerde pnömotoraks ve akciğer dokusunda kollaps izlendi. 


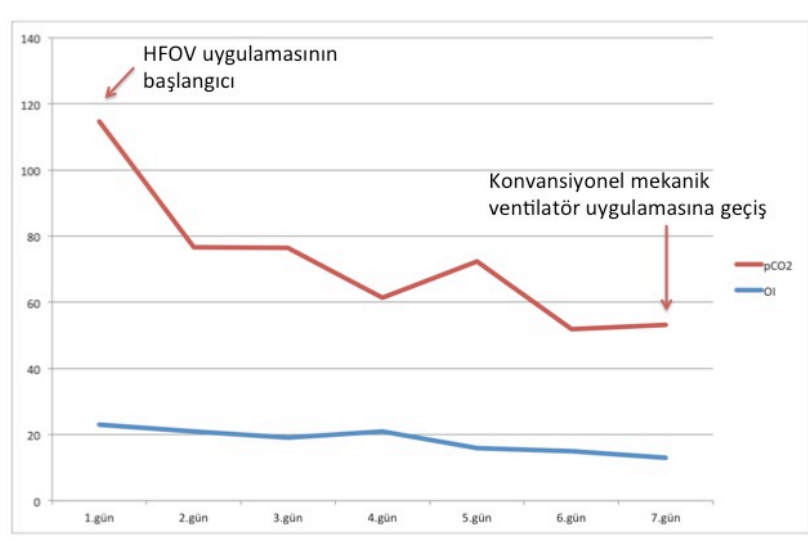

Şekil 1. Yüksek frekans ossilasyon ventilasyon uygulaması tedavisi ile parsiyel karbondioksit basıncı ve oksijen indeksindeki değişiklikler.

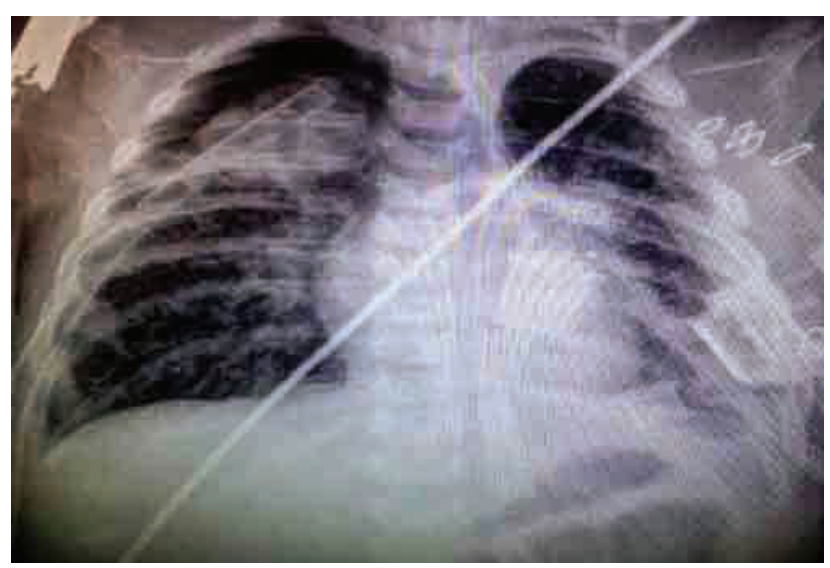

Figür 3. Sağ akciğerde de pnömotoraks saptanması üzerine sağ tarafa da gögüs tüpü yerleştirildi.

patoloji saptanmadı. Arteriyel kan gazında; $\mathrm{pH}: 7.31$ $\mathrm{pCO}_{2}: 60.2 \mathrm{mmHg} \mathrm{pO}_{2}: 86,9 \mathrm{mmHg} \mathrm{HCO}_{3}: 29.7 \mathrm{mmol} / \mathrm{L}$ saptandı. Ventilatör parametrelerinden frekans 35/ dk. ve PIP $27 \mathrm{~cm} \mathrm{H} \mathrm{H}_{2}$ 'a arttırıldı. Kontrol kan gazında $\mathrm{pH}: 7.16 \mathrm{pCO}_{2}: 87.1 \mathrm{mmHg} \mathrm{pO}_{2}: 63.7 \mathrm{mmHg} \mathrm{HCO}_{3}: 30.2$ $\mathrm{mmol} / \mathrm{L}$ saptanması üzerine frekans $40 / \mathrm{dk}$., IT: 0,5 olacak şekilde değiştirildi. Bakılan kontrol kan gazında $\mathrm{pH}: 7,01$ ve $\mathrm{pCO}_{2}: 115 \mathrm{mmHg}$ olması nedeniyle hasta mekanik ventilatörden ayrıldı ve yüksek frekans ossilasyon ventilasyon uygulaması (HFOV) (3100A HFOV-CareFusion) uygulaması başlatıldı. Başlangıç ayarları olarak F:8 Hz, Paw:25 cm H $2, \Delta P: 50, I T: \% 33$, $\mathrm{FiO}_{2}: 1$ belirlendi. Kan gazı takiplerinde respiratuvar asidozun düzeldiği ve oksijenasyon indeksinin azaldığı görüldü. HFOV uygulaması ile kan gazı parametre değişiklikleri Şekil 1'de gösterilmiştir. Dört kez mekanik ventilasyon tedavisine geçiş yapıldı, ancak $\mathrm{pCO}_{2}$

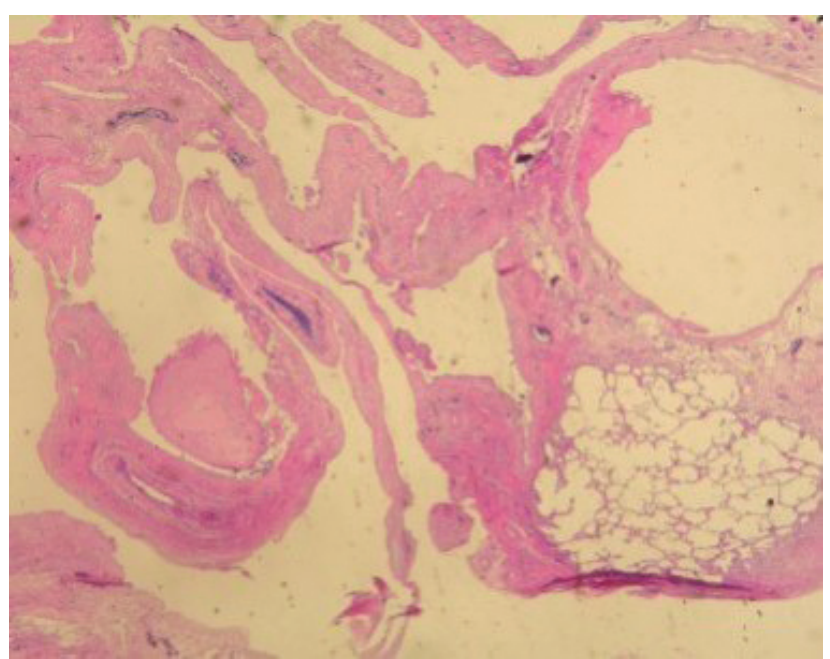

Figür 4. Akciğer biyopsisi, fibröz duvarla çevrili kistik yapılar (H\&E×40).

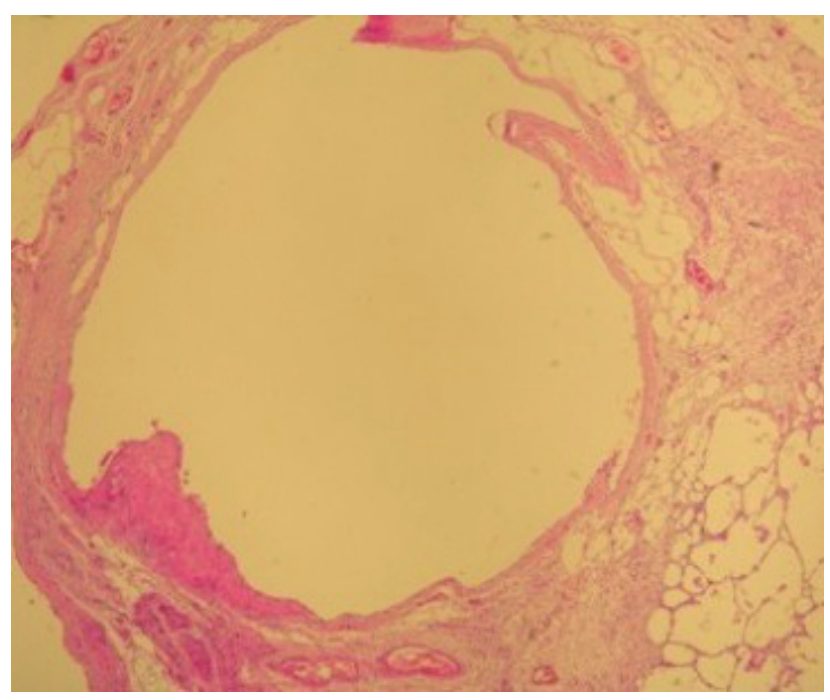

Figür 5. Akciğer biyopsisi, fibröz duvarla çevrili kistik yapılar (H\&E×100).

değerinin hızla yükselmesi üzerine yeniden HFOV uygulamasına geçildi. Yedinci günde konvansiyonel mekanik ventilasyona geçildikten sonra kan gazı kontrolünde $\mathrm{pH}: 7.42 \mathrm{pCO}_{2}: 40.8 \mathrm{mmHg}, \mathrm{pO}_{2}: 188 \mathrm{mmHg}$, $\mathrm{HCO}_{3}: 23.7 \mathrm{mmol} / \mathrm{L}$ saptand, invaziv mekanik ventilasyon tedavisine devam edildi. PA Akciğer grafisinde sağda da pnömotoraks oluştuğu gözlendi, hasta Göğüs Cerrahisi Kliniği ile konsülte edildi, sağ tarafa da göğüs tüpü takıldı (Resim 3). Tanısal amaçlı akciğer wedge rezeksiyon yapıldı, patolojik incelemede fibröz duvarla çevrili kistik yapılar izlendi, bu bulgularla kistik adenomatoid malformasyon tanısı kondu (Resim 4 ve 5). Yatışının 26. gününde kademeli olarak 
ventilatörden ayrıldı, T tüpe geçildi, spontan soluma testinin başarılı olması nedeniyle hasta ekstübe edildi. Nazal kanül ile yüksek akış tedavisi başlandı ve 10 gün devam edildi. Yatışının 38. gününde oksijen tedavisi kesildi. Göğüs tüpü çekilen ve vital bulguları stabil seyreden hasta pediatri servisine devredildi.

\section{TARTIŞMA}

Akciğerin hamartomatöz bir lezyonu olarak KKAM, birbirleriyle ilişkili prolifere terminal bronşioller, kistik ve solid yapılar ile karakterize doğumsal bir anomalidir. Konjenital akciğer malformasyonlarının $\% 25$ 'ini ve konjenital kistik akciğer malformasyonlarının \%95'ini oluşturur. Erkeklerde daha sık görülür $r^{5}$.

KKAM, yenidoğan döneminde ciddi ve ilerleyici solunum sıkıntısına, çocuk ya da yetişkinlerde ise tekrarlayan akciğer infeksiyonlarına neden olur. Fizik muayenede, etkilenmiş tarafta göğsün belirgin olması, hiperrezonans, azalmış solunum sesleri, kalp seslerinin derinden gelmesi ve kalbin karşı tarafa yer değiştirmesi gibi bulgular bulunabilir 6 . Olgumuzda doğum sırasında solunum sıkıntısı olmamıştı, ancak 3 ve 5 aylıkken olmak üzere iki kez akciğer infeksiyonu tanısı ile hospitalize edilmişti. Son yatışında ise tekrarlayan pnömotoraks nedeniyle göğüs tüpü ile takip edilerek ayırıcı tanıya gidilmişti.

KKAM olgularının \%18-20'sine Prune Belly, pulmo- ner sekestrasyon, diyafragma hernisi, karşı akciğerin agenezisi, renal ve kardiyak anomaliler eşlik edebilir? Hastamızın abdomen USG incelemesi normaldi, ekokardiyografik incelemesinde patoloji saptanmadı.

KKAM, patolojik karakteristikleri açısından 5 tipe ayrılır ${ }^{8,9}$. Tablo $1^{\prime}$ de tipleri, insidansı ve özellikleri belirtilmiştir. Olgumuz toraks BT'de her iki akciğerde yaygın çok sayıda küçük çaplı $(0,5-1 \mathrm{~cm})$ kistler saptanması nedeniyle Tip 2 olarak değerlendirildi.

Prenatal tanı Ultrasonografi (USG) ile olası olabilir. Çap 5 mm'nin altında olan kistler ekojenik ve solid görüntülenirler. Polihidramnioz, hidrops, pulmonerhipoplazi ve mediastenin yer değiştirmesi saptanabilir $^{10}$. Hastamızın annesi gebeliği boyunca düzenli olarak kontrollere gitmiş, ancak yapılan USG incelemelerinde bir anomaliden söz edilmemişti.

Postnatal dönemde KKAM tanısı akciğer grafisi ve toraks $\mathrm{BT}$ incelemesi ile konabilir. Prenatal tanı konan hastalarda postnatal dönemde tanı akciğer filmi ile doğrulanır, altıncı aya kadar bir kez hastalara yüksek çözünürlüklü akciğer tomografisi çekilmesi önerilmektedir $^{11}$. Direkt radyografide boyutları değişken ve mediastinal şifte neden olabilen çoklu kistler görülebilir. Ancak yaşamın ilk günlerinde bu kistlerin içi sıvı dolu olduğundan grafide homojen dens görünümler olabilir. Bu sıvılar bronşiyal, lenfatik ve dolaşım sistemi tarafından zamanla emildikçe kistler radyolüsen hâle gelirler. Tomografi lezyonların yaygınlığı, kistik

Tablo 1. Konjenital kistik adenomatoid malformasyon tipleri, insidansı ve özellikleri.

\begin{tabular}{lccl}
\hline Tip & İnsidans (\%) & Kist Çapı & Özellikler \\
\hline Tip 0 & 1 -3 & Max. çap 0,5 cm & $\begin{array}{l}\text { Doğumda kaybedilirler. } \\
\text { Kardiyovasküler anomali ve dermalhipoplazi olabilir. }\end{array}$ \\
\hline Tip 1 & $60-70$ & $2-10 \mathrm{~cm}$ & $\begin{array}{l}\text { Malign potansiyele sahiptir. Yüzde 95 tek lob tutulumu vardır. } \\
\text { Kist tek ya da multipl olabilir. Prognozu iyi }\end{array}$ \\
\hline Tip 2 & $15-20$ & $0,5-1 \mathrm{~cm}$ & $\begin{array}{l}\text { Yaygın multipl kist vardır. Pulmoner sekestrasyon sıktır. } \\
\text { Kardiyak, renal ve kromozom anomalileri olabilir. En kötü prognoza sahiptir. }\end{array}$ \\
\hline Tip 3 & $5-10$ & $<0,5 \mathrm{~cm}$ & Multipl kist, bir ya da birkaç lobu tutabilir. \\
\hline Tip 4 & $10-15$ & Max. çap 7 cm & $\begin{array}{l}\text { Sıklıkla tansiyon pnömotoraks ve infeksiyon ile birliktedir. Plöropulmoner blastom ile yakın } \\
\text { ilişkilidir. }\end{array}$ \\
\hline
\end{tabular}


S. Erdoğan et al., Congenital cystic adenomatoid malformation case diagnosed in the first six months of life and applıcation of HFOV in respiratory failure due to pneumothorax

yapısı ve varsa konsolide alanlar veya başka yapısal anomaliler hakkında bilgi verir. Sauvat ve ark. ${ }^{12}$ yaptıkları bir çalışmada, asemptomatik olan ve prenatal KKAM tanısı alan infantların \%41'nin doğumda akciğer grafilerinin normal olduğunu, yapılan toraks BT incelemesi ile \%91'inde kistik akciğer anomalilerinin görüntülenebildiğini gösterdiler.

Bronkopulmoner sekestrasyon, konjenital diyafragmatik herni, bronkojenik kist, konjenital lober amfizem, lokalize pulmoner interstisyel amfizem, pnömatosel ile ayırıcı tanı yapılmalıdır. Pnömatoselde adenomatoid malformasyonda görülene benzer bir şekilde kompleks epitelyal ve stromal kompenent mevcut değildir. Lober amfizemde kistler arası mesafede alveollere rastlanmaz. Yüz yetmiş iki hasta içeren bir seride KKAM'li hastaların \%71'inde bronkopulmoner sekestrasyonun eşlik ettiği ve sıklıkla Tip 2 ile birlikteliği gösterildi ${ }^{13}$.

Intrauterin 32. haftadan önce saptanan ve hidrops gelişmiş KKAM olgularında fetal cerrahi prosedürler uygulanmalı ve fetal cerrahi deneyimi olan merkezlere transfer gerçekleştirilmelidir. Otuz ikinci haftadan sonraki hidrops olgularında ise erken doğum düşünülmeli ve cerrahi rezeksiyon uygulanmalıdır ${ }^{14}$. Pulmoner rezeksiyon yapılan çocuk ve genç erişkinlerde prognoz çok iyidir. Uygulanan cerrahi teknik kitlenin büyüklüğüne göre lobektomiden pnömonektomiye kadar değişebilir. Ancak, tüm akciğeri tutan yaygın lezyonlarda total pulmonektomi gerekliliği vardır. Bu olgularda mortalite yüksektir ve akciğer transplantasyonu gereklidir ${ }^{15,16}$. Mortalite oranı $\% 5^{\prime}$ tir, solunum yetmezliği, sepsis, mekanik ventilasyon gereksinimi ve eşlik eden ağır komorbiditeler mortalite için risk faktörleridir. Olgumuzda da solunum yetmezliği gelişti, hastaya invaziv mekanik ventilasyon uygulandı, ancak solunumsal asidozun devam etmesi nedeniyle solunumunun yönetimine HFOV ile devam edildi. HFOV tedavisi ilk kez 1980'li yılların başında klinik olarak kullanılmaya başlanmıştır. Konvansiyonel mekanik ventilasyonda uygulanması bazı zorluklar içeren akciğer koruyucu stratejiler ile etkili ventilasyon arasındaki dengeyi kolaylaştırır. En önemli iki özelliği, suprafizyolojik solunum sayıları ve anatomik ölü boş- luktan daha düşük tidal hacimlerdir. Konvansiyonel mekanik ventilasyona göre avantajları, daha düşük hacim ve basınç değişiklikleri, siklik gerilimin ortadan kalkması, distal hava yollarında belirgin ölçüde daha düşük basınçlarda etkin gaz değişimi ve endojen sürfaktan üretiminin daha az baskılanmasıdır. Daha önce KKAM'li hastalarda HFOV kullanımına ilişkin literatür verisine rastlamadık. Ancak travma sonrası hava kaçağı sendromu gelişen ve HFOV ile tedavi edilen 2 olgu sunumu rapor edilmişti ${ }^{17,18}$. Ağır pulmoner kontüzyona bağlı akut respiratuvar distres sendromu gelişen 17 erişkin hastada HFOV uygulamasının güvenli ve etkili olduğu, oksijenasyon indeksinde hızlı iyileşmeye yolaçtığı bildirilmiştir ${ }^{19}$. Akut pulmoner disfonksiyonu olan yenidoğan hastalarda HFOV uygulamasının invaziv mekanik ventilasyona göre, yeni hava kaçağı sendromu oluşumunu azaltma potansiyeline sahip olduğu belirtilmektedir ${ }^{20}$. Hastamızda 7 günlük HFOV uygulaması sonrası hiperkarbi düzeldi ve invaziv mekanik ventilasyona geçilebildi.

KKAM, ender görülmekle birlikte, yineleyen akciğer infeksiyonu ve akciğerde kistik lezyonu olan hastaların ayırıcı tanısında düşünülmelidir. Solunum yetmezliği gelişen hastalarda konvansiyonel MV ile düzeltilemeyen hipoksi ya da hiperkarbi durumlarında HFOV uygulaması alternatif bir tedavi seçeneği olabilir.

\section{KAYNAKLAR}

1. Laberge JM, Flageole $H$, Pugash D, et al. Outcome of the prenatally diagnosed congenital cyctic adenomatoid lung malformation. A Canadian experience. Fetal Diagn Ther 2001; 16: $178-86$. http://dx.doi.org/10.1159/000053905

2. Shanti CM, Klein MD. Cyctic lung disease. Semin Pediatr Surgery 2008; 17: 2. http://dx.doi.org/10.1053/j.sempedsurg.2007.10.002

3. Lujan M, Bosque M, Mirapeix RM. Late - oncet congenital cyctic adenomatoid malformation of the lung. Embryology, clinical symptomatology, diagnostic procedures, therapeutic approach and clinical follow-up. Respiration 2002; 69: 14854.

4. Parikh D, Samuel M. Congenital cyctic lung lesions: is surgical resection essential? Pediatr Pulmonol 2005; 40: 533-7. http://dx.doi.org/10.1002/ppul.20300

5. Wilson RD, Hedrick HL, Liechty KW, et al. Cyctic adenomatoid malformation of the lung: Review of genetics, prenatal diagnosis, and inutero treatment. Am J Med Genet 2006; 140: 151-5. http://dx.doi.org/10.1002/ajmg.a.31031 
6. Sittig SE, Asay GF. Congenital cyctic adenomatoid malformation in the newborn: two case studies and review of the literature. Respiratory Care 2000; 45: 1188-95.

7. Fowler $\mathrm{CL}$, Johnson L, Shukla P, et al. Congenital cyctic adenomatoid malformation of the lung. SDJ Med 1987; 40: 5-8.

8. Priest JR, Williams GM, Hill DA, et al. Pulmonary cycts in early childhood and the risk of malignancy. Pediatr Pulmonol 2009; 44: 14-30. http://dx.doi.org/10.1002/ppul.20917

9. Berrocal T, Madrid C, Novo S, et al. Congenital anomalies of the tracheobronchial tree, lung, and mediastinum: embryology, radiology, and pathology. Radiographics 2004; 24: e.17.

10. Adzick NS, Harrison MR, Crombleholme TM, et al. Fetal lung lesions:management and outcome. Am J Obstet Gynecol 1998; 179: 884-9. http://dx.doi.org/10.1016/S0002-9378(98)70183-8

11. Köstel S, Onay ÖS, Tuğral $M$ ve ark. Prenatal konjenital kistik adenomatoid malformasyon tanısı alan bebeklerin postnatal izlemi. Turk Ped J 2013; 56: 71-75.

12. Sauvat F, Michel JL, Benachi A, et al. Management of asymptomatic neonatal cyctic adenomatoid malformations. $J \mathrm{Pe}$ diatr Surg 2003; 38: 548-52. http://dx.doi.org/10.1053/jpsu.2003.50119

13. Giubergia V, Barrenechea $M$, Siminovich $M$, et al. Congenital cyctic adenomatoid malformation:clinical features, pathological concepts and management in 172 cases. J Pediatr 2012; 88: 143-8.

http://dx.doi.org/10.2223/JPED.2177
14. Sugıyama M, Honna T, Kamil Y, et al. Management of prenatally diagnosed congenital cyctic adenomatoid malformation of the lung. Eur J Pediatr Surg 1999; 9: 53-7. http://dx.doi.org/10.1055/s-2008-1072214

15. Muller CO, Berrebi D, Knecihne A. Is radical lobectomy required in congenital cyctic adenomatoid malformation? J Pediatr Surg 2012; 47: 642-5.

http://dx.doi.org/10.1016/j.jpedsurg.2011.08.002

16. Calvert JK, Lakhoo K. Antenatally suspected congenital cyctic adenomatoid malformation of the lung: postnatal investigation and timing of surgery. J Pediatr Surg 2007; 42: 411-4. http://dx.doi.org/10.1016/j.jpedsurg.2006.10.015

17. Dallessio JJ, Markley MA, Lohe A, et al. Management of a traumatic pulmonary pseudocyst using high-frequency oscillatory ventilation. J Trauma 1995; 39: 1188-90. http://dx.doi.org/10.1097/00005373-199512000-00034

18. Soni KD, Aggarwal R, Gupta A, et al. Is the use of high frequency oscillatory ventilator beneficial in managing severe chest injury with massive air leak? BMJ Case Rep 2014 Nov 5.doi:10.1136/bcr-2014-204284. http://dx.doi.org/10.1136/bcr-2014-204284

19. Funk DJ, Lujan E, Moretti EW, et al. A brief report: the use of high-frequency oscillatory ventilation for severe pulmonary contusion. J Trauma 2008; 65: 390-5. http://dx.doi.org/10.1097/TA.0b013e31817f283f

20. Jeng MJ, Lee YS, Tsao PC, et al. Neonatal air leak syndrome and the role of high-frequency ventilation in its prevention. $J$ Chin Med Assoc 2012; 75: 551. http://dx.doi.org/10.1016/j.jcma.2012.08.001 